\title{
Cardiac Rehabilitation Costs
}

Mahshid Moghei a, Karam Turk-Adawi ${ }^{\text {b }}$, Wanrudee Isaranuwatchai ${ }^{\text {c }}$, Nizal Sarrafzadegan ${ }^{\text {d* }}$, Paul Oh ${ }^{\mathrm{e}}$, Caroline Chessex ${ }^{\mathrm{e}}$, and Sherry L. Grace ${ }^{\mathrm{a}, \mathrm{e}}$,

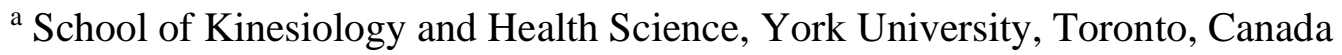

${ }^{\mathrm{b}}$ Department of Public Health, Qatar University, Al-Doha, Qatar

${ }^{\mathrm{c}}$ Institute of Health Policy, Management and Evaluation, University of Toronto, Toronto, Canada

${ }^{\mathrm{d}}$ Isfahan University of Medical Sciences, Isfahan, Iran and School of Population and Public Health, University of British Columbia, Vancouver, Canada

${ }^{\mathrm{e}}$ University Health Network, University of Toronto, Canada

*Corresponding author at: Isfahan Cardiovascular Research Centre, Cardiovascular Research Institute, Isfahan University of Medical Sciences, Khorram Avenue, PO Box 81465-1148, Isfahan, Iran

E-mail address: nsarrafzadegan @gmail.com (N. Sarrafzadegan)

The authors report no relationships that could be construed as a conflict of interest. 


\section{Abstract}

Background: Despite the clinical benefits of cardiac rehabilitation (CR) and its costeffectiveness, it is not widely received. Arguably, capacity could be greatly increased if lowercost models were implemented. The aims of this review were to describe: the costs associated with CR delivery, approaches to reduce these costs, and associated implications.

Methods: Upon finalizing the PICO statement, information scientists were enlisted to develop the search strategy of MEDLINE, Embase, CDSR, Google Scholar and Scopus. Citations identified were considered for inclusion by the first author. Extracted cost data were summarized in tabular format and qualitatively synthesized.

Results: There is wide variability in the cost of CR delivery around the world, and patients pay out-of-pocket for some or all of services in 55\% of countries. Supervised CR costs in highincome countries ranged from PPP\$294 (Purchasing Power Parity; 2016 United States Dollars) in the United Kingdom to PPP $\$ 12,409$ in Italy, and in middle-income countries ranged from PPP $\$ 146$ in Venezuela to PPP\$1095 in Brazil. Costs relate to facilities, personnel, and session dose. Delivering CR using information and communication technology (mean cost PPP \$753/patient/program), lowering the dose and using lower-cost personnel and equipment are important strategies to consider in containing costs, however few explicitly low-cost models are available in the literature.

Conclusion: More research is needed regarding the costs to deliver CR in community settings, the cost-effectiveness of $\mathrm{CR}$ in most countries, and the economic impact of return-to-work with CR participation. A low-cost model of CR should be standardized and tested for efficacy across multiple healthcare systems. 
Key words

Cardiac Rehabilitation, Cardiovascular Diseases, Cost, Developing Countries, Developed Countries, Economics 


\section{Introduction}

Cardiovascular disease (CVD) is one of the most prevalent health conditions worldwide[1]. This burden is particularly problematic in low and middle-income countries (LMICs), where more than $80 \%$ of CVD deaths occur[2].CVD is also among the leading causes of disability[3]; The percentage of years lived with disability has increased by $25 \%$ globally since 2005[4].

Individuals with CVD are at high risk for subsequent major cardiac events and death[5], thus secondary prevention is paramount. Cardiovascular rehabilitation (CR) is an effective and low-cost model of care for secondary prevention of CVD. It is an outpatient chronic disease management program[6], delivering the core components of assessment, medical risk factor management, structured exercise training, patient education as well as psychosocial and behavioral counselling (e.g., diet, tobacco)[7,8]. CR is generally delivered in a clinical setting such as a hospital, and patients come on-site on average 3 times/week for 5 months[9]. CR participation results in a $26 \%$ reduction in cardiovascular mortality and $18 \%$ reduction in costly re-hospitalization compared to usual care.[10]

The cost-effectiveness of CR has been demonstrated across many contexts and perspectives (e.g.,[11-14]). In a systematic review of 9 cost-effectiveness studies by Wong et al.[15], it was concluded that supervised CR could be cost-effective compared to no CR. Three studies compared supervised versus home-based CR, and four studies home-based versus no CR. Results showed that home-based CR was equivalently cost-effective when compared to supervised CR, and was cost-saving when compared to no CR.

The above research was undertaken mainly in high-income countries. In a recent review on the economics of CR in LMICs by Oldridge et al.[16], studies were identified in Brazil and 
Colombia, and both showed CR as cost-effective in patients with heart failure. Obviously there would be many differences between high-income countries and LMICs which would influence the cost-effectiveness of CR. Overall, the literature suggests that across settings, type of program, population, and perspective, $\mathrm{CR}$ is an economically-attractive option compared to no CR.

Despite the clinical and economic benefits of CR, it is not widely implemented[17,18], particularly in LMICs where it could be especially beneficial. In this resource-constrained era, lower-cost models may be more feasibly implemented on a broad scale; this could enable reach to a greater number of patients in need, and hence have a greater impact at the population-level. Therefore, the objectives of this review were to: (1) describe the costs associated with delivering CR, (a) as well as its individual components, (b) by delivery setting (e.g., home-based), and (c) by country income classification (i.e., high and LMIC), (2a) describe approaches to lowering delivery costs, and (b) lower-cost models of CR, as well as (3) consider implications for society, health systems and research.

\section{Cost of Delivering Supervised Cardiac Rehabilitation}

Traditional CR consists primarily of supervised exercise sessions delivered in an outpatient setting, such as a hospital or clinic. Overall, delivering the traditional model of CR carries with it costs associated with personnel, equipment and other supplies, space and other operating costs[19-21] Only a handful of studies have reported all costs to run a program per patient (see also[20,22,23] for costs to run alternative models). For example, the study by Oldridge et al. in Canada reported direct costs for a 16-session supervised program were: space \$290CAD (1987; Purchasing Power Parity PPP\$506 in 2016 dollars), overall personnel \$148 (PPP\$258), equipment \$64 (PPP\$112), and resource literature \$5 (PPP\$9), for a total of 
\$PPP884 [19]. The study by Whittaker et al. reported the costs of 6-week supervised program were overall \$1845AUD (2013; PPP\$1,312), comprised of facility \$595 (PPP\$423), administration \$450 (PPP\$320), coaching and mentoring \$225 (PPP\$160), assessment \$195 (PPP\$139), gymnasium \$180 (PPP\$128), communications \$125 (PPP\$89), technology \$40 (PPP\$28) and education \$35 (PPP\$25) costs[20].

The available literature on CR personnel costs specifically is displayed in Table 1. Given the multi-component nature of $\mathrm{CR}$, and hence the multiple disciplines required to deliver it comprehensively, personnel costs are quite high. There is wide variation in the staffing complement of CR programs, as well as program policies around staff-to-patient ratios during exercise for safety[24-26]; correspondingly overall costs to programs would vary. As shown, there was no available literature on the costs of occupational therapy within the CR setting; this is a significant omission considering the importance of return-to-work to patients and society. The value of the personnel with respect to achieving beneficial patient outcomes is not reflected, but strategies to mitigate these costs are considered below.

The available literature on the cost of delivering each of the core CR components is displayed in Table 2. As shown, there was no available data regarding costs for the non-patientcare related component of program audit and evaluation. For some medications and smoking cessation, data was available for cost of secondary prevention but outside of CR settings.

The overall cost of delivering supervised CR was expressed on a per patient (for a complete program), or per session basis in the literature (no studies were identified reporting the cost to run a program per year for example). Table 3 summarizes the available data on the cost to deliver CR by country, sorted by country income classification. These costs are considerably less 
expensive than the cost of acute cardiac procedures[18]. In high-income countries (HICs), the cost to deliver a supervised CR session ranged from PPP\$12 in Finland to PPP\$310 in Italy.

Available data on supervised CR delivery costs in LMICs is also shown in Table 3. As shown, there is only information on delivery in MICs in South America. Costs were also reported in Mexico, but only the range of \$600-3400USD[27]. In most countries, delivery costs are higher in private versus public healthcare. Unfortunately, whether these costs can be attributed to differences in CR care quality in these settings is not known, but the lower cost is likely due to higher volume of patients (personal communication, Claudia Anchique Santos, December 18, 2016). The review by Oldridge et al. juxtaposed these overall CR costs in relation to healthcare expenditure per capita[16]. It was concluded that CR as delivered traditionally was not affordable in the LIC setting, but was in MICs. However, clearly CR is delivered at much lower cost than in HICs, and what evidence is available suggests equivalent benefits are achieved[17].

Finally, one must consider costs to patients to attend CR. It is hoped that patients do not have to pay for CR care, however in a snowball survey of CR associations globally, it was found that patients pay out-of-pocket for some or all of the program costs in 55\% of countries[28]. Patients attending supervised programs also have to incur expenses related to transportation (including parking), as well as time costs. These have been characterized in a few studies[19,20,29,30], and can be considerable. Indeed, a review of CR barriers in LMICs cited affordability for patients[31]. Lost productivity to attend supervised sessions must also be considered[22].

\section{Broad Approaches to Reducing Cost of Cardiac Rehabilitation Delivery}


The literature review revealed several approaches to lowering the cost of CR. These were delivering CR in unsupervised settings, task-shifting to lower-cost healthcare personnel, and offering a lower dose (i.e., fewer sessions). Other approaches were also raised, including using lower-cost exercise equipment, and ceasing ECG-monitoring during exercise sessions[32,33].

\section{Setting}

Given patient-related barriers to attending traditional, supervised CR[34], and limits on capacity in these settings, alternative delivery settings have been established. CR is now delivered in primary care practices, outpatient clinics, community facilities, as well as patient's homes (including via information and communication technologies [i.e., tele- or internet-based rehabilitation or eCR, and via mobile/smart phone or $\mathrm{mCR}]$ ). Evidence generally supports the equivalent efficacy of $\mathrm{CR}$ as delivered across these settings[23,35-38]. Available data on cost to deliver CR in these various settings is shown in Table 4. A study undertaken in Belgium is not shown[39], as the tele-CR was delivered in addition to supervised CR, however results of this hybrid approach was more effective and less costly than CR alone. Delivering CR in a hospital setting is often considered the most costly, due to the costs for space and potentially care receipt by more specialized (and hence costlier) personnel such as cardiologists[37].

However, reviews have established that the cost to deliver home-based CR is equivalent to that of supervised CR[23,35,40]. While there is not agreed-upon consensus definition, homebased CR generally involved a patient coming on-site for an initial assessment, during which an exercise prescription would be developed. Then exercise training is performed without formal supervision, and regular 1-1 follow-ups are conducted via phone (i.e., landline) including provision of all other core CR components. The cost equivalence could be due to the fact that home-based CR is generally delivered individually rather than in a group, requiring more 
personnel hours on a per-patient basis. However, the out-of-pocket cost to patients is cheaper, as they will not incur travel costs (including parking) to attend each session[20]. As outlined below, by exploiting technology, home-based CR could potentially be delivered not on a 1-1 basis, but one staff could reach more than the typical number of patients served in a group supervised program; in this instance, eCR could potentially be lower-cost.

CR is also delivered in community settings. As evidenced by Table 4, the cost of CR delivery in these settings is not well known. This model of CR delivery may particularly be less costly if the community facility permits CR staff to use their space and equipment at no or low $\operatorname{cost}[32,33]$. There may be insurance costs associated with delivery in these settings however, so that personnel are not liable for clinical events in their patients. Given there are often more recreation facilities in communities than hospitals, patients may incur lower out-of-pocket costs travelling to these centers due to proximity.

Finally, there are other ways by which eCR could be more cost-efficient than reduced overhead costs, such as maximizing patient volume. Given the newness of this area, it is not yet known how many patients can be served effectively and safely per full-time equivalent/personnel[33], and hence indeed how cost-efficient this model of care has the potential to be. Moreover, many features of the online environment can be exploited to cheaply and/or freely deliver many of the core CR components. For example, patients could complete online assessments (e.g., depression screening, medications, diet; and there are validated, free tools available) to shorten the amount of personnel time required for initial assessment. Patients could enter their lifestyle behavior in an online monitoring program which could also reduce the time required for patient lifestyle counselling (i.e., focusing only on areas where patients are not achieving treatment targets). Peer support for lifestyle risk factor management could be exploited 
at no cost within this context, again reducing the need for CR personnel. Similarly using accelerometry within a smartphone, CR personnel could be alerted when exercise guidelines are not met, and only follow-up with patients in need, or automatically-generated texts could be used to "nudge" these non-adherent participants[41]. Additionally, patient education can be delivered via the internet (including "how-to" videos for resistance training for example, animations regarding cardiac anatomy and CVD therapies) without personnel once developed[42]. With regard to medical risk factor management, patients could be periodically screened for medication adherence, blood pressure and tobacco cessation persistence, and only those requiring support would then be contacted by CR personnel. In addition, one of the mCR programs published incorporated relaxation audio files for stress management[43].

\section{Personnel \&Task-shifting}

As outlined above, personnel are an expensive aspect to CR delivery (Table 1). These costs can be minimized by reducing the amount of patient contact (through the mCR strategies above or reducing dose as outlined below), or by providing care by the lowest-cost yet competent, trained provider. The American Association of Cardiovascular and Pulmonary Rehabilitation, European Association of Preventive Cardiology, and Canadian Association of Cardiovascular Prevention and Rehabilitation recommend that CR programs be led by a cardiologist, to ensure the utmost safety of patients[24]. However, given their specialized training, cardiologist compensation is expensive and hence this requirement (which may be an artifact of reimbursement requirements) is quite costly (particularly given there is no evidence to show that safety is compromised where a cardiologist [or generalist physician for that matter] is not present). Other countries such as the Netherlands and United Kingdom, recommend that a general physician, exercise physiologist, physiotherapist, allied healthcare provider, or another 
staff member trained in exercise prescription would be sufficient to supervise exercise sessions[24,26].

In the International Council of Cardiovascular Prevention and Rehabilitation consensus statement regarding CR delivery in low-resource settings, recommendations for how each of the core $\mathrm{CR}$ components can be provided whether by a nurse, allied healthcare professional or even a community healthcare worker are provided[32]. However, safety and efficacy must be considered, particularly as there have been no studies to our knowledge on the effect of healthcare provider type in the CR setting. Certainly, nurse-led programs for secondary prevention of CVD more broadly have been shown to be safe and efficacious[44].

\section{Dose}

Given there is an expense associated with delivering each CR session, CR cost will differ based on program duration and frequency of sessions (i.e., dose). As outlined in the review of CR guidelines by Price et al.[24], program duration recommendations vary considerably around the world from two weeks to 5 months. A review revealed that dose ranges from 16.5 sessions in France to 142 in Spain[9]; This is a large variation of 125.5 sessions. The median duration was 12 weeks and the median session dose was 30. The highest doses were reported in Saudi Arabia, Germany and Canada, while the lowest doses were reported in France and Italy[9].

Recent research suggests that a minimum of 12 sessions should be delivered to achieve improved outcomes, but 36 may have additional benefit[9]. While further research is needed to establish a minimum effective CR threshold, if we consider the average cost per session in HICs is PPP\$59 (i.e., mean from Table 3), and a median of 30 sessions are delivered in HICs[9], PPP $\$ 1,062$ could be saved per patient if dose was reduced to 12 sessions. Comparably, if we consider the average cost per session in MICs is PPP\$10 (to the public healthcare system, again 
Table 3), and on average 36 sessions are delivered in MICs[9], then PPP\$240 could be saved per patient with a 12 session program.

\section{Other Approaches to Reducing the Cost of CR Delivery}

Other strategies raised in the literature included not monitoring patients with telemetry every session (particularly if safety has been established and the patient has no history of ventricular arrhythmias),[45] and not requiring a graded exercise stress test at intake assessment as the basis for exercise prescription but rather using a 6-minute walk test[32,33]. Arguably the impetus for both of these practices are non-evidence-based reimbursement requirements and profit generation, respectively. To our knowledge, there is no data suggesting CR participants achieve greater outcomes where their exercise prescription is based on a graded exercise stress test than a simpler functional capacity test. Moreover, the cost of equipment (e.g., \$64 [1987USD\$] for an 8-week CR program)[19] can be reduced by using less-expensive alternates such as community trails for walking and running rather than treadmills, and cans rather than dumbbells as weights for strength training[32,33].

Finally, these CR cost-reducing approaches could be combined, and directed to patients who are considered at low-risk of an acute event during exercise (and hence appropriate for unsupervised settings) and/or present with uncomplicated CVD and no comorbidities (and hence could be treated by non-physicians) and/or have high health literacy and psychosocial well-being (and hence could undertake patient education independently on the web and receive fewer CR sessions)[46]. Arguably, this would represent the majority of cardiac outpatients. Alternatively, patients could receive CR care in a supervised setting until safety has been established, and then transitioned to eCR - a so-called "hybrid" model.

\section{Lower-Cost Models of Cardiac Rehabilitation Delivery}


Low-cost models of CR delivery warrant characterization (e.g., [32,33]) and an evidence base. Through this review, only a couple of studies presenting a specifically "lower-cost" model of $\mathrm{CR}$ and a few protocols underway were identified. First, Carlson et al.[45] developed a hybrid program to reduce cost. This program involved 3 ECG-monitored exercise sessions per week for the first month (which is the norm in the United States due to reimbursement requirements), which transitioned to unsupervised exercise for six months, with telephone follow-up and educational support. The lower-cost model was clinically beneficial - participants exercised more, and had similar improvements in maximal oxygen uptake, blood lipids, and hemodynamic measurements than participants exposed to traditional CR. Importantly, this model costs PPP $\$ 2117$ patient, which is $\$ 738$ USD less than the traditional model, and required 30\% less staff (full-time equivalents).

Thankfully many randomized trials now incorporate cost analyses, and hence some information on cost of alternative models such as eCR can also be gleaned from these sources[20,47] (Table 4). There are also quite a few trials of eCR currently underway, examining both efficacy and cost-effectiveness (e.g., NCT02717806). For instance, Kraal et al.[48] has a low-cost tele-monitoring guided home-based CR program under investigation (only efficacy results published to date). Another protocol underway is the SmartCare-CAD trial evaluating effects and costs of a tele-rehabilitation program.[49]

Clearly, more work needs to be done to standardize a low-cost CR model (considering dose, personnel, setting, etc), test its efficacy, acceptability and implementability in real-world practice, as well as establish its affordability across multiple healthcare systems. We must also consider how patients are allocated to various models of care, and ensure we are providing the lower-cost model to as many indicated patients as possible. 


\section{Societal Perspective: Cost-Savings Due to Averted Healthcare Utilization and Return to Work}

Participating in CR has been shown to result in lower healthcare utilization (not necessarily physician visits which are planned for preventive care and routine follow-up, but emergency department visits due to recurrent events or revascularization) and hence lower care costs.[39,50][51] Many studies report less healthcare utilization and re-hospitalization costs in patients who attend CR compared to those who do not attend. Table 5 summarizes a selection of these studies. A recent review has also established equivalent healthcare usage following supervised and home-based CR[35], suggesting similar reductions would be achieved regardless of setting.

Return-to-work is one of the main goals of many CR participants. Indeed, patients who participate in CR are more likely to return than those who do not[12,52], although there is not much recent research in this important area. Thus, they pay taxes, buy more products, support their families and contribute to society, benefiting themselves as well as the community. Unsupervised models of CR, such as eCR, can be accessed outside of work hours, hence enabling return-to-work and optimizing recovery.

\section{Future Directions and Implications}

In addition to those outlined above, some areas for research in this field are particularly pressing. For instance, current cost-effectiveness data are needed in every region, as health systems and other factors vary. Furthermore, the minimum dose of low-cost CR to be effective, including in vulnerable subgroups such as those with comorbidities, women, and older patients, needs to be determined. 
With regard to policy implications, chief is reimbursement. In order to widely implement the low-cost models of CR that are shown to be safe and effective, these types of services must be reimbursable by government or private healthcare insurers. Currently, there is incredibly wide variation in reimbursement globally[26,27], with patients paying out-of-pocket for some or all of CR services in 55\% of countries[28]. Restrictive, non-evidence-based criteria for reimbursement should be abolished, so flexible models of care can be delivered that meet the needs of patients in a cost-effective manner. For instance, home-based CR is just starting to be reimbursed in the United States, and in Japan few centers are authorized by government to offer CR[53]. We need more reimbursement for $\mathrm{CR}$ to reduce out-of-pocket costs for patients, and hence increase their participation. This in turn will result in more cost-savings to the health system, due to reduced CVD interventions and re-hospitalization[51]. Finally, reimbursement must be sufficient to cover program delivery expenses, as a review of CR barriers in LMICs cited inability to make a profit[31].

To achieve broad-scale delivery of low-cost CR, we need to develop capacity of nonphysician CR providers. Core competencies have been established[54,55]. The American Association of Cardiovascular and Pulmonary Rehabilitation and The British Association for Cardiovascular Prevention and Rehabilitation offer certification for a variety of allied healthcare professionals[56,57]. The International Council of Cardiovascular Prevention and Rehabilitation is developing such a program for healthcare professionals in low-resource settings. CR providers also need to be trained to incorporate new technologies into their care models.

Let us challenge the CR community to develop a \$99USD model of CR that is comprehensive, safe, effective and implementable on a wide-scale. This should be possible given 
the penetrance of smartphones in the current era and positive results shown in initial trials[43]. We can then translate and cross-culturally adapt to deliver this model across more countries.

In conclusion, $\mathrm{CR}$ is considered cost-effective and cost-saving. The cost of traditional supervised CR delivery varies widely across the globe (but is unknown in most LMICs); this is likely due to variation in operating/facility costs, as well as for personnel. Setting, personnel, dose and equipment of CR can be modified, to reduce costs and hence enable reach to a greater number of patients within current resource availability. Low-cost models such as the one described by Carlson et al[45]. should be implemented more widely given its safety and efficacy. eCR should be exploited to optimize cost-efficiencies, as it has been shown to be as effective as traditional CR.

\section{Acknowledgements}

We thank Rajiv Nariani and Maureen Pakosh for their help with the literature search. 


\section{References}

[1] S. Mendis, P. Puska, B. Norrving, Global Atlas on cardiovascular disease prevention and control, Geneva, Switzerland, 2011. http://whqlibdoc.who.int/publications/2011/9789241564373_eng.pdf.

[2] A.E. Moran, M.H. Forouzanfar, G.A. Roth, et al., The global burden of ischemic heart disease in 1990 and 2010: The global burden of disease 2010 study, Circulation. 129 (2014) 1493-1501. doi:10.1161/CIRCULATIONAHA.113.004046.

[3] T. Vos, A.D. Flaxman, M. Naghavi, et al., Years lived with disability (YLDs) for 1160 sequelae of 289 diseases and injuries 1990-2010: a systematic analysis for the Global Burden of Disease Study 2010, Lancet. 380 (2012) 2163-2196. doi:10.1016/S01406736(12)61729-2.

[4] T. Vos, C. Allen, M. Arora, et al., Global, regional, and national incidence, prevalence, and years lived with disability for 310 diseases and injuries, 1990-2015: a systematic analysis for the Global Burden of Disease Study 2015, Lancet. 388 (2016) 1545-1602. doi:10.1016/S0140-6736(16)31678-6.

[5] D.M. Kolansky, Acute coronary syndromes: morbidity, mortality, and pharmacoeconomic burden., Am. J. Manag. Care. 15 (2009) S36-S41. doi:11084 [pii].

[6] J.A. Stone, N. Suskin, H.M. Arthur, Canadian guidelines for cardiac rehabilitation and cardiovascular disease prevention: Translating knowledge into action. 3rd ed, 3rd ed., Canadian Association of Cardiac Rehabilitation, Winnipeg, Manitoba, Canada, 2009.

[7] J.P. Buckley, G. Furze, P. Doherty, et al., BACPR scientific statement: British standards and core components for cardiovascular disease prevention and rehabilitation, Heart. 99 (2013) 1069-1071. doi:10.1136/heartjnl-2012-303460.

[8] G.J. Balady, M.A. Williams, P.A. Ades, et al., Core Components of Cardiac Rehabilitation/Secondary Prevention Programs: 2007 Update: A Scientific Statement From the American Heart Association Exercise, Cardiac Rehabilitation, and Prevention Committee, the Council on Clinical Cardiology; the Councils o, Circulation. 115 (2007) 2675-2682. doi:10.1161/CIRCULATIONAHA.106.180945.

[9] C. Santiago de Araujo Pio, S. Marzolini, M. Pakosh, S.L. Grace, Dose of Cardiac Rehabilitation Across the Globe, Toronto Gen. Res. Inst. Res. Day. (2016).

[10] L. Anderson, N. Oldridge, D.R. Thompson, et al., Exercise-Based Cardiac Rehabilitation for Coronary Heart Disease, J. Am. Coll. Cardiol. 67 (2016) 1-12. doi:10.1016/j.jacc.2015.10.044.

[11] P.A. Ades, F.J. Pashkow, J.R. Nestor, Cost-Effectiveness of Cardiac Rehabilitation After Myocardial Infarction, J. Cardiopulm. Rehabil. 17 (1997) 222-231. doi:10.1097/00008483-199707000-00002.

[12] L.A. Levin, J. Perk, B. Hedbäck, Cardiac rehabilitation--a cost analysis., J. Intern. Med. 230 (1991) 427-34. http://www.ncbi.nlm.nih.gov/pubmed/1940778 (accessed September 21, 2014).

[13] P. Dendale, D. Hansen, J. Berger, M. Lamotte, Long-term cost-benefit ratio of cardiac rehabilitation after percutaneous coronary intervention., Acta Cardiol. 63 (2008) 451-6. doi:10.2143/AC.63.4.2033043.

[14] L.E. Leggett, T. Hauer, B.J. Martin, et al., Optimizing Value from Cardiac Rehabilitation A Cost-Utility Analysis Comparing Age, Sex, and Clinical Subgroups, Mayo Clin. Proc. 90 (2015) 1011-1020. doi:10.1016/j.mayocp.2015.05.015. 
[15] W.P. Wong, J. Feng, K.H. Pwee, J. Lim, A systematic review of economic evaluations of cardiac rehabilitation., BMC Health Serv. Res. 12 (2012) 243. doi:10.1186/1472-6963-12243.

[16] N.B. Oldridge, M.T. Pakosh, R.J. Thomas, Cardiac rehabilitation in low- and middleincome countries: A review on cost and cost-effectiveness, Int. Health. 8 (2015) 77-82. doi:10.1093/inthealth/ihv047.

[17] K.I. Turk-Adawi, S.L. Grace, Narrative review comparing the benefits of and participation in cardiac rehabilitation in high-, middle- and low-income countries., Heart. Lung Circ. 24 (2015) 510-20. doi:10.1016/j.hlc.2014.11.013.

[18] K. Turk-Adawi, N. Sarrafzadegan, S.L. Grace, Global availability of cardiac rehabilitation., Nat. Rev. Cardiol. 11 (2014) 586-96. doi:10.1038/nrcardio.2014.98.

[19] N. Oldridge, W. Furlong, D. Feeny, et al., Economic evaluation of cardiac rehabilitation soon after acute myocardial infarction., Am J Cardiol. 72 (1993) 154-161. http://www.ncbi.nlm.nih.gov/pubmed/8328376 (accessed June 24, 2011).

[20] F. Whittaker, V. Wade, The costs and benefits of technology-enabled, home-based cardiac rehabilitation measured in a randomised controlled trial., J. Telemed. Telecare. 20 (2014) 419-22. doi:10.1177/1357633X14552376.

[21] S. Papadakis, R.D. Reid, D. Coyle, L. Beaton, D. Angus, N. Oldridge, Cost-effectiveness of cardiac rehabilitation program delivery models in patients at varying cardiac risk, reason for referral, and sex., Eur. J. Cardiovasc. Prev. Rehabil. 15 (2008) 347-53. doi:10.1097/HJR.0b013e3282f5ffab.

[22] T.B. Hansen, A.D. Zwisler, S.K. Berg, et al., Cost-utility analysis of cardiac rehabilitation after conventional heart valve surgery versus usual care, Eur. J. Prev. Cardiol. 24 (2017) $1-10$.

[23] R.S. Taylor, H. Dalal, K. Jolly, et al., Home-based versus centre-based cardiac rehabilitation, Cochrane Database Syst. Rev. 340 (2015) CD007130. doi:10.1002/14651858.CD007130.pub2.

[24] K.J. Price, B.A. Gordon, S.R. Bird, A.C. Benson, A review of guidelines for cardiac rehabilitation exercise programmes: Is there an international consensus?, Eur. J. Prev. Cardiol. 23 (2016) 1715-33. doi:10.1177/2047487316657669.

[25] K.I. Turk-Adawi, C. Terzic, B. Bjarnason-Wehrens, S.L. Grace, Cardiac rehabilitation in Canada and Arab countries: comparing availability and program characteristics, BMC Health Serv. Res. 15 (2015) 521. doi:10.1186/s12913-015-1183-7.

[26] B. Bjarnason-Wehrens, H. McGee, A.D. Zwisler, et al., Cardiac rehabilitation in Europe: results from the European Cardiac Rehabilitation Inventory Survey., Eur. J. Cardiovasc. Prev. Rehabil. 17 (2010) 410-8. doi:10.1097/HJR.0b013e328334f42d.

[27] H. Ilarraza-lomelí, M. García-saldivia, J. Rojano-castillo, et al., National Registry of Cardiac Rehabilitation Programs in Mexico II ( RENAPREC II ), Arch. Cardiol. Mex. (2016). http://dx.doi.org/10.1016/j.acmx.2016.04.010.

[28] A.S. Babu, F. Lopez-Jimenez, R.J. Thomas, et al., International Council of Cardiovascular Prevention and Rehabilitation (ICCPR), Advocacy for outpatient cardiac rehabilitation globally., BMC Health Serv. Res. 16 (2016) 471. doi:10.1186/s12913-016-1658-1.

[29] S. Ali, M. Moghei, M. Krahn, C. Chessex, S.L. Grace, Healthcare Utilization and Associated Time and Out-of-Pocket Expenditures for Cardiovascular Disease Patients, Can. J. Cardiol. (2017) Provisionally Accepted.

[30] S.D. Reed, D.J. Whellan, Y. Li, et al., Economic evaluation of the HF-ACTION (Heart 
Failure: A Controlled Trial Investigating Outcomes of Exercise Training) randomized controlled trial: an exercise training study of patients with chronic heart failure, Circ Cardiovasc Qual Outcomes. 3 (2010) 374-381.

doi:10.1161/CIRCOUTCOMES.109.907287.

[31] L. Ragupathi, J. Stribling, Y. Yakunina, V. Fuster, M.A. McLaughlin, R. Vedanthan, Availability, Use, and Barriers to Cardiac Rehabilitation in LMIC, Glob. Heart. (2017). doi:10.1016/j.gheart.2016.09.004.

[32] S.L. Grace, K. Turk-Adawi, A. Contractor, et al., Cardiac rehabilitation delivery model for low-resource settings: An International Council of Cardiovascular Prevention and Rehabilitation consensus statement., Prog. Cardiovasc. Dis. In Press (2016).

[33] S.L. Grace, K.I. Turk-Adawi, A. Contractor, et al., Cardiac rehabilitation delivery model for low-resource settings, Heart. 102 (2016) 1449-1455. doi:10.1136/heartjnl-2015309209.

[34] S. Shanmugasegaram, P. Oh, R.D. Reid, T. McCumber, S.L. Grace, A comparison of barriers to use of home- versus site-based cardiac rehabilitation., J. Cardiopulm. Rehabil. Prev. 33 (2013) 297-302. doi:10.1097/HCR.0b013e31829b6e81.

[35] S.A. Buckingham, R.S. Taylor, K. Jolly, et al., Home-based versus centre-based cardiac rehabilitation: Abridged Cochrane systematic review and meta-analysis, Open Hear. 3 (2016) 1-16. doi:10.1136/openhrt-2016-000463.

[36] K. Huang, W. Liu, D. He, et al., Telehealth interventions versus center-based cardiac rehabilitation of coronary artery disease: A systematic review and meta-analysis, Eur. J. Prev. Cardiol. 22 (2015) 959-971. doi:10.1177/2047487314561168.

[37] R.A. Clark, A. Conway, V. Poulsen, W. Keech, R. Tirimacco, P. Tideman, Alternative models of cardiac rehabilitation: a systematic review., Eur. J. Prev. Cardiol. 22 (2015) 3574. doi:10.1177/2047487313501093.

[38] J.C. Rawstorn, N. Gant, A. Direito, C. Beckmann, R. Maddison, Telehealth exercise-based cardiac rehabilitation: a systematic review and meta-analysis., Heart. 102 (2016) 11831192. doi:10.1136/heartjnl-2015-308966.

[39] I. Frederix, D. Hansen, K. Coninx, P. et al., Effect of comprehensive cardiac telerehabilitation on one-year cardiovascular rehospitalization rate, medical costs and quality of life: A cost-effectiveness analysis., Eur. J. Prev. Cardiol. 23 (2016) 674-82. doi:10.1177/2047487315602257.

[40] A.D. Zwisler, R.J. Norton, S.G. Dean, et al., Home-based cardiac rehabilitation for people with heart failure: A systematic review and meta-analysis, Int. J. Cardiol. 221 (2016) 963 969. doi:10.1016/j.ijcard.2016.06.207.

[41] C.K. Chow, J. Redfern, G.S. Hillis, et al., Effect of Lifestyle-Focused Text Messaging on Risk Factor Modification in Patients With Coronary Heart Disease, J. Am. Med. Assoc. 314 (2015) 1255. doi:10.1001/jama.2015.10945.

[42] G.L. de Melo Ghisi, Development of an Educational Curriculum for Cardiac Rehabilitation Patients and their Families, J. Clin. Exp. Cardiolog. 6 (2015). http://www.omicsonline.org/open-access/development-of-an-educational-curriculum-forcardiac-rehabilitation-patients-and-their-families-2155-9880-1000373.php?aid=54299.

[43] M. Varnfield, M. Karunanithi, C.K. Lee, et al., Smartphone-based home care model improved use of cardiac rehabilitation in postmyocardial infarction patients: results from a randomised controlled trial., Heart. 100 (2014) 1770-9. doi:10.1136/heartjnl-2014305783. 
[44] S.B. Connolly, K. Kotseva, C. Jennings, et al., Outcomes of an integrated communitybased nurse-led cardiovascular disease prevention programme, Heart. (2017) heartjnl2016-310477. doi:10.1136/heartjnl-2016-310477.

[45] J.J. Carlson, J.A. Johnson, B.A. Franklin, R.L. VanderLaan, Program participation, exercise adherence, cardiovascular outcomes, and program cost of traditional versus modified cardiac rehabilitation., Am. J. Cardiol. 86 (2000) 17-23. http://www.ncbi.nlm.nih.gov/pubmed/10867086 (accessed June 11, 2014).

[46] S.L. Grace, K. Turk-Adawi, C.S. de A. Pio, D.A. Alter, Ensuring cardiac rehabilitation access for the majority of those in need: A call to action for Canada, Can. J. Cardiol. 32 (2016) S358-S364. doi:10.1016/j.cjca.2016.07.001.

[47] B.H. Southard, D.R. Southard, J. Nuckolls, Clinical trial of an Internet-based case management system for secondary prevention of heart disease, J. Cardiopulm. Rehabil. 23 (2003) 341-348.

[48] J.J. Kraal, N. Peek, M.E. van den Akker-Van Marle, H.M. Kemps, Effects and costs of home-based training with telemonitoring guidance in low to moderate risk patients entering cardiac rehabilitation: The FIT@Home study, BMC Cardiovasc. Disord. 13 (2013) 82. doi:http://dx.doi.org/10.1186/1471-2261-13-82.

[49] R.W.M. Brouwers, J.J. Kraal, S.C.J. Traa, R.F. Spee, L.M.L.C. Oostveen, H.M.C. Kemps, Effects of cardiac telerehabilitation in patients with coronary artery disease using a personalised patient-centred web application: protocol for the SmartCare-CAD randomised controlled trial, BMC Cardiovasc. Disord. 17 (2017) 46. doi:10.1186/s12872017-0477-6.

[50] A. Brown, R. Taylor, H. Noorani, J. Stone, B. Skidmore, Exercise-Based Cardiac Rehabilitation Programs for Coronary Artery Disease: A Systematic Clinical and Economic Review, Canadian Coordinating Office of Health Technology Assessment (CCOHTA), Ottawa, Canada, 2003. http://www.cadth.ca/en/products/health-technologyassessment/publication/398 (accessed September 30, 2012).

[51] D.A. Alter, B. Yu, R.R. Bajaj, P.I. Oh, Relationship Between Cardiac Rehabilitation Participation and Health Service Expenditures Within a Universal Health Care System, Mayo Clin. Proc. 92 (2017) 500-511. doi:10.1016/j.mayocp.2016.12.024.

[52] E. Simchen, I. Naveh, Y. Zitser-Gurevich, D. Brown, N. Galai, Is participation in cardiac rehabilitation programs associated with better quality of life and return to work after coronary artery bypass operations? The Israeli CABG Study., Isr. Med. Assoc. J. 3 (2001) 399-403. http://www.ncbi.nlm.nih.gov/pubmed/11433629.

[53] Y. Goto, Current state of cardiac rehabilitation in Japan, Prog. Cardiovasc. Dis. 56 (2014) 557-562. doi:10.1016/j.pcad.2013.12.001.

[54] L.F. Hamm, B.K. Sanderson, P.A. Ades, et al., Core competencies for cardiac rehabilitation/secondary prevention professionals: 2010 update: position statement of the American Association of Cardiovascular and Pulmonary Rehabilitation., J. Cardiopulm. Rehabil. Prev. 31 (2011) 2-10. doi:10.1097/HCR.0b013e318203999d.

[55] S.H.M. Lin, L. Neubeck, R. Gallagher, Educational Preparation, Roles, and Competencies to Guide Career Development for Cardiac Rehabilitation Nurses., J. Cardiovasc. Nurs. 0 (2016). doi:10.1097/JCN.0000000000000346.

[56] The American Association of Cardiovascular and Pulmonary Rehabilitation Certification, (n.d.). https://www.aacvpr.org/Certification/AACVPR-Professional-Certification.

[57] The British Association of Cardiovascular Prevention and Rehabilitation Certification, 
(n.d.). http://www.bacpr.com/pages/page_box_contents.asp?pageid=851\&navcatid=182.

[58] K. Jolly, R. Taylor, G.Y.H. Lip, et al., The Birmingham Rehabilitation Uptake

Maximisation Study (BRUM). Home-based compared with hospital-based cardiac rehabilitation in a multi-ethnic population: cost-effectiveness and patient adherence, Health Technol. Assess. 11 (2007) 1-118. doi:10.3310/hta11350.

[59] J. Ladapo, F.A. Jaffer, M.C. Weinstein, Projected cost-effectiveness of smoking cessation interventions in patients hospitalized with myocardial infarction, Arch. Intern. Med. 171 (2011) 39-45. http://archinte.amaassn.org/cgi/reprint/171/1/39\%5Cnhttp://ovidsp.ovid.com/ovidweb.cgi?T=JS\&PAGE=ref erence $\& D=e m e d 10 \& N E W S=N \& A N=2011030874$.

[60] N. Lang, K. Fox, Current drug therapies used in the secondary prevention of MI, Prescriber. 21 (2010) 22-45. doi:10.1002/psb.675.

[61] D. Fidan, B. Unal, J. Critchley, S. Capewell, Economic analysis of treatments reducing coronary heart disease mortality in England and Wales, 2000-2010, Q. J. Med. 100 (2007) 277-289. doi:10.1093/qjmed/hcm020.

[62] L. Collins, P. Scuffham, Y. Health, E. Consortium, S. Gargett, P. Health, Cost-analysis of gym-based versus home-based cardiac rehabilitation programs, Aust. Heal. Rev. 24 (2001) 51-61.

[63] J.P. Hall, V.L. Wiseman, M.T. King, et al., Economic evaluation of a randomised trial of early return to normal activities versus cardiac rehabilitation after acute myocardial infarction, Hear. Lung Circ. 11 (2002) 10-18. doi:10.1046/j.1444-2892.2002.00105.x.

[64] A.J. Hautala, A.M. Kiviniemi, T. Mäkikallio, et al., Economic evaluation of exercisebased cardiac rehabilitation in patients with a recent acute coronary syndrome, Scand. J. Med. Sci. Sport. (2016) 1-9. doi:10.1111/sms.12738.

[65] N. Marchionni, F. Fattirolli, S. Fumagalli, et al., Improved exercise tolerance and quality of life with cardiac rehabilitation of older patients after myocardial infarction: Results of a randomized, controlled trial, Circulation. 107 (2003) 2201-2206.

doi:10.1161/01.CIR.0000066322.21016.4A.

[66] R.S. Taylor, A. Watt, H.M. Dalal, et al., Home-based cardiac rehabilitation versus hospital-based rehabilitation: A cost effectiveness analysis, Int. J. Cardiol. 119 (2007) 196-201.

[67] A. Cowie, O. Moseley, Home- versus hospital-based exercise training in heart failure: An economic analysis, Br. J. Cardiol. 21 (2014) 76. doi:10.5837/bjc.2014.011.

[68] C.V. Anchique Santos, F. Lopez-Jimenez, B. Benaim, et al., Cardiac rehabilitation in Latin America, Prog. Cardiovasc. Dis. 57 (2014) 268-275. doi:10.1016/j.pcad.2014.09.006.

[69] X.M. Salvetti, J.A. Oliveira, D.M. Servantes, A.A. Vincenzo de Paola, How much do the benefits cost? Effects of a home-based training programme on cardiovascular fitness, quality of life, programme cost and adherence for patients with coronary disease., Clin. Rehabil. 22 (2008) 987-96. doi:10.1177/0269215508093331.

[70] N.H. Miller, D. Warren, D. Myers, MULTIFIT study model, J. Cardiovasc. Nurs. 11 (1996) 76-87.

[71] N. Giacomantonio, C. Skedgel, W. Firth, L. Lethbridge, A Mortality Advantage at 2 Years When Attending a Community Based CR Program With Minimal and Insignificant Healthcare Costs. Now That's a Deal!, Can. J. Cardiol. 29 (2013) S156. doi:http://dx.doi.org/10.1016/j.cjca.2013.07.232. 
[72] K. Kidholm, M.K. Rasmussen, J.J. Andreasen, et al., Cost-Utility Analysis of a Cardiac Telerehabilitation Program: The Teledialog Project, Telemed. J. E. Health. 22 (2016) 55363. doi:10.1089/tmj.2015.0194. 
Table 1. Summary of Findings Regarding Healthcare Personnel Costs for Supervised Cardiac Rehabilitation Delivery

\begin{tabular}{lccc}
\hline Healthcare Provider Type & $\begin{array}{c}\text { Cost currency } \\
\text { year) }\end{array}$ & Per Patient Per & PPP (2016) \\
\hline Physicians & Program & $\$ 205$ \\
Specialist (e.g., Cardiologist)[19] & $\$ 118(1987$ CAD) & Hour & $\$ 60$ \\
Generalist/Primary Care[12] & $236(1988$ SEK) & Hour & $\$ 97$ \\
Nurse[58] & $£ 50(2002)$ & & $\$ 75$ \\
\hline Allied Healthcare Workers[58] & $£ 39(2002)$ & Hour & $\$ 75$ \\
Dietitian & $£ 39(2002)$ & Hour & $\$ 75$ \\
Exercise physiologist & $£ 39(2002)$ & Hour & \\
Physiotherapist & & & $\$$ \\
\hline
\end{tabular}

PPP, Purchasing Power Parity; CAD, Canadian Dollar; SEK, Swedish Krona; £, British Pound 
Table 2. Summary of Findings Regarding Cost to Deliver Cardiac Rehabilitation Components in a Supervised Setting

\begin{tabular}{|c|c|c|c|}
\hline Core Component & $\begin{array}{c}\text { Cost } \\
\text { (currency year) }\end{array}$ & Per Patient Per & $\begin{array}{c}\text { PPP } \\
(2016)\end{array}$ \\
\hline $\begin{array}{l}\text { Patient Assessment } \\
{[58]} \\
{[20]}\end{array}$ & $\begin{array}{l}£ 50(2002) \\
\$ 195(2013) \dagger\end{array}$ & $\begin{array}{l}\text { Hour } \\
\text { Program }\end{array}$ & $\begin{array}{l}\$ 97 \\
\$ 139\end{array}$ \\
\hline \multicolumn{4}{|l|}{ Lifestyle Risk Factor Management } \\
\hline $\begin{array}{l}\text { Smoking cessation*[59] } \\
\text { Nicotine Replacement Therapy } \\
\text { Bupropion } \\
\text { Varenicline }\end{array}$ & $\begin{array}{l}\text { \$263(2008USD) } \\
\text { \$246(2008USD) } \\
\text { \$361(2008USD) }\end{array}$ & $\begin{array}{l}\text { Program } \\
\text { Program } \\
\text { Program }\end{array}$ & $\begin{array}{l}\$ 293 \\
\$ 274 \\
\$ 402\end{array}$ \\
\hline Exercise Training[21] & \$110(2004USD) & Program & $\$ 140$ \\
\hline Lifestyle counselling[21] & \$167(2004USD) & Program & $\$ 212$ \\
\hline Coaching and Mentoring[20] & $\$ 225(2013 \mathrm{AUD}) \dagger$ & Program & $\$ 160$ \\
\hline \multicolumn{4}{|l|}{$\begin{array}{l}\text { Medical Risk Factor Management } \\
\text { and Cardioprotective Therapies }\end{array}$} \\
\hline Risk factor counselling[21] & $\$ 75$ (2004USD) & Program & $\$ 95$ \\
\hline $\begin{array}{l}\text { ACE-Inhibitors*[60] } \\
\text { Ramipril }\end{array}$ & $£ 18$ (2007) & Month & $\$ 30$ \\
\hline $\begin{array}{l}\text { Antiplatelets*[60] } \\
\text { Aspirin }\end{array}$ & $£ 1.4(2007)$ & Month & $\$ 2.3$ \\
\hline $\begin{array}{l}\text { Beta-blockers*[60] } \\
\text { Metoprolol }\end{array}$ & $£ 2.6(2007)$ & Month & $\$ 4$ \\
\hline Diuretics[12] & 272 (1988SEK) & Year & $\$ 68$ \\
\hline $\begin{array}{l}\text { Statins*[61] } \\
\quad \text { Pravastatin[60] }\end{array}$ & $\begin{array}{l}£ 387(2000) \\
£ 7.5(2007)\end{array}$ & $\begin{array}{l}\text { Year } \\
\text { Month }\end{array}$ & $\begin{array}{l}\$ 615 \\
\$ 12\end{array}$ \\
\hline Nitrates[12] & 469 (1988SEK) & Year & $\$ 117$ \\
\hline \multicolumn{4}{|l|}{ Psychosocial Health } \\
\hline Psychosocial counselling[21] & $\$ 93$ (2004USD) & Program & $\$ 118$ \\
\hline Patient Education[20] & \$35 (2013AUD) & Program & $\$ 25$ \\
\hline
\end{tabular}


CR, Cardiac Rehabilitation; PPP, Purchasing Power Parity; ACE, Angiotensin Converting Enzyme; AUD, Australian Dollar; USD, United States Dollar; £, British Pound

*Not in cardiac rehabilitation setting

$\uparrow$ Y ear of currency not stated in study, therefore, date of the costs/benefits model development by the author was reported and used for PPP calculation 
Table 3. Summary of Findings Regarding Cost to Deliver Supervised Cardiac Rehabilitation Programs, by Country Income Classification*

\begin{tabular}{|c|c|c|c|c|c|}
\hline Country & $\begin{array}{c}\text { CR } \\
\text { Dose }\end{array}$ & $\begin{array}{c}\text { Session } \\
\text { Cost/Patient } \\
\text { (Currency Year) }\end{array}$ & $\begin{array}{l}\text { Session PPP } \\
\quad(2016)\end{array}$ & $\begin{array}{c}\text { Program } \\
\text { Cost/Patient }\end{array}$ & $\begin{array}{c}\text { Program PPP } \\
(2016)\end{array}$ \\
\hline \multicolumn{6}{|l|}{ High-Income } \\
\hline Australia[62]† & 32 & $\$ 60$ (1998AUD) & $\$ 68$ & $\$ 1,933$ & $\$ 2,181$ \\
\hline Australia[63] & 14 & \$28 (1999AUD) & $\$ 31$ & $\$ 394$ & $\$ 438$ \\
\hline Australia[20]† & NR & NR & - & $\$ 1,845$ & $\$ 1,312$ \\
\hline Canada[19] & 16 & $\$ 36$ (1987CAD) & $\$ 56$ & $\$ 570$ & $\$ 884$ \\
\hline Canada [21]§ & 33 & \$16 (2004USD) & $\$ 20$ & $\$ 518$ & $\$ 663$ \\
\hline Denmark[22] & 36 & $€ 25$ (2014) & $\$ 34$ & $€ 882$ & $\$ 1,217$ \\
\hline Finland[64] & 28 & $€ 11(2015)$ & $\$ 12$ & $€ 299$ & $\$ 335$ \\
\hline Italy[65] & 40 & $\$ 221$ (2000USD) & $\$ 310$ & $\$ 8,841$ & $\$ 12,409$ \\
\hline United Kingdom[66] & 9 & $£ 22(2002)$ & $\$ 43$ & $£ 200$ & $\$ 388$ \\
\hline United Kingdom[58] & 16 & $£ 10(2003)$ & $\$ 18$ & $£ 157$ & $\$ 294$ \\
\hline United Kingdom[67] & 16 & $£ 14(2013)$ & $\$ 21$ & $£ 222$ & $\$ 329$ \\
\hline United States[11] & 36 & $\$ 36$ (1995USD) & $\$ 57$ & $\$ 1,305$ & $\$ 2,057$ \\
\hline United States[45]† & 98 & \$24 (1999USD) & $\$ 35$ & $\$ 2,349$ & $\$ 3,387$ \\
\hline Mean (Median) & & & & & $\$ 1,991(\$ 884)$ \\
\hline
\end{tabular}




\begin{tabular}{cccccc}
\hline Middle-Income[68] & & $\ddagger$ & & & \\
$\begin{array}{c}\text { Upper-MIC } \\
\text { Argentina }\end{array}$ & 36 & $7 / 8$ & $7 / 8$ & $252 / 288$ & $255 / 292$ \\
Brazil & 36 & $10 / 30$ & $10 / 30$ & $360 / 1,080$ & $365 / 1,095$ \\
Colombia & 36 & $10 / 22$ & $10 / 22$ & $360 / 792$ & $365 / 803$ \\
Peru & 36 & $9 / 12$ & $9 / 12$ & $324 / 432$ & $328 / 438$ \\
Venezuela & 36 & $4 / 6$ & $4 / 6$ & $144 / 216$ & $146 / 219$ \\
Lower-MIC & & $6 / 7$ & & & \\
Bolivia & 36 & $25 / 17$ & $6 / 7$ & $216 / 252$ & $219 / 255$ \\
Paraguay & 36 & & $25 / 17$ & $900 / 612$ & $912 / 620$ \\
Mean (Median) & & & & $\$ 370 / \$ 532$ \\
\hline
\end{tabular}

CR, Cardiac Rehabilitation; NR, Not Reported; PPP, Purchasing Power Parity; MIC, MiddleIncome Country; AUD, Australian Dollar; USD, United States Dollar

*Income classifications based on World Bank

(https://datahelpdesk.worldbank.org/knowledgebase/articles/906519)

$\dagger$ Year of currency not stated in study, and therefore first year of data collection is reported and used for PPP calculation.

$\S$ The "standard CR" model with 33 sessions of exercise over a 3-month period.

₹ All in 2014 USD\$. First value represents cost per session delivered under public healthcare, and the latter value is the cost for these sessions delivered within the private healthcare system (i.e., patients would require private insurance coverage or pay out-of-pocket). 
Table 4. Summary of Findings Regarding Cost of Delivering Alternative Cardiac Rehabilitation Models

\begin{tabular}{|c|c|c|c|c|}
\hline $\begin{array}{l}\text { CR Model } \\
\text { Country }\end{array}$ & $\begin{array}{c}\text { Duration in } \\
\text { months }\end{array}$ & $\begin{array}{l}\text { Cost Per Patient } \\
\text { Per Program }\end{array}$ & PPP (2016) & PPP/Month \\
\hline \multicolumn{5}{|l|}{ Home-based CR } \\
\hline Australia[62] & 12 & $\$ 1,169$ (1998AUD)* $^{*}$ & $\$ 1,320$ & $\$ 110$ \\
\hline Brazil[69] & 3 & $\$ 503$ (2008USD) & $\$ 561$ & $\$ 187$ \\
\hline Italy[65] & 2 & $\$ 1,650$ (2000USD) & $\$ 2,316$ & $\$ 1,158$ \\
\hline United Kingdom[66] & 1.5 & $£ 170$ (2002) & $\$ 329$ & $\$ 219$ \\
\hline United Kingdom[58] & 1.5 & $£ 198$ (2003) & $\$ 371$ & $\$ 247$ \\
\hline United Kingdom[67] & 2 & $£ 197$ (2013) & $\$ 292$ & $\$ 146$ \\
\hline United States[70] & 12 & $\$ 552$ (1991USD)* & $\$ 972$ & $\$ 81$ \\
\hline Mean (Median) & & & $\$ 880(\$ 561)$ & $\$ 307(\$ 187)$ \\
\hline \multicolumn{5}{|l|}{ Community-based CR } \\
\hline Canada[71] & 3 & $\$ 1,175(2013 \mathrm{CAD})$ & $\$ 988$ & 329 \\
\hline \multicolumn{5}{|l|}{$e C R$} \\
\hline Australia[20] & 1.5 & $\$ 1,633$ (2013AUD)* & $\$ 1,161$ & $\$ 774$ \\
\hline Denmark[72] & 3 & $€ 392$ (2015) & $\$ 532$ & $\$ 177$ \\
\hline United States[47] & 6 & $\$ 453$ (2001USD)* & $\$ 613$ & $\$ 102$ \\
\hline Mean (Median) & & & $\$ 769(\$ 613)$ & $\$ 351(177)$ \\
\hline
\end{tabular}

CR, Cardiac Rehabilitation; PPP, Purchasing Power Parity; MIC, Middle-Income Country; UK, United Kingdom; US, United States; AUD, Australian Dollar; USD, US Dollar

*Year of currency not stated in study, and therefore first year of data collection is reported and used for PPP calculation. 
Table 5. Selected Findings Regarding Cost Savings Due to Averted Healthcare Utilization with Cardiac Rehabilitation

\begin{tabular}{|c|c|c|c|c|}
\hline Country & Currency & Healthcare Costs & Findings & PPP (2016) \\
\hline $\begin{array}{l}\text { Belgium } \\
(2008)[13]\end{array}$ & $2005 €$ & $\begin{array}{l}\text { Rehospitalization and } \\
\text { revascularization }\end{array}$ & $\begin{array}{c}\text { Total cost /patient } € 636 \text { lower in CR } \\
\text { group vs no CR during 4.5-year } \\
\text { follow-up }\end{array}$ & $\$ 876$ \\
\hline Canada (2017)[51] & 2016CAD & $\begin{array}{l}\text { Rehospitalization, drugs, } \\
\text { physician visits, ER visits }\end{array}$ & $\begin{array}{l}\text { Costs } \$ 2,920 / \text { year lower in CR } \\
\text { participants than non-participants } \\
\text { during 36-month follow-up }\end{array}$ & $\$ 2,349$ \\
\hline Canada (1993)[19] & 1987CAD & $\begin{array}{l}\text { Physician, ER and allied } \\
\text { health visits, } \\
\text { rehospitalization, other } \\
\text { rehab }\end{array}$ & $\begin{array}{l}\text { Total direct savings per patient } \$ 260 \\
\text { in CR group vs. no CR }\end{array}$ & $\$ 454$ \\
\hline $\begin{array}{l}\text { Denmark } \\
(2016)[22]\end{array}$ & $2014 €$ & $\begin{array}{l}\text { Primary and secondary } \\
\text { care, drugs, productivity } \\
\text { loss and patient-borne costs }\end{array}$ & $\begin{array}{c}\text { Cost/patient } € 1,609 \text { lower in CR } \\
\text { group vs. no CR during 6-month } \\
\text { follow-up }\end{array}$ & $\$ 2,176$ \\
\hline Sweden (1991)[12] & 1988SEK & $\begin{array}{l}\text { Rehospitalization, } \\
\text { revascularization, drugs, } \\
\text { outpatient clinic, time and } \\
\text { travel and productivity loss }\end{array}$ & $\begin{array}{c}\text { Total costs/patient SEK 73,510 } \\
\text { lower in CR group vs. no CR during } \\
\text { 5-year follow-up }\end{array}$ & $\$ 18,412$ \\
\hline $\begin{array}{l}\text { United States } \\
\text { (1997)[11] }\end{array}$ & 1995USD & Rehospitalization & $\begin{array}{l}\text { Cost savings/patient } \$ 1,870 \text { in CR } \\
\text { group vs no CR over mean of } 21 \\
\text { months post-cardiac event }\end{array}$ & $\$ 2,945$ \\
\hline $\begin{array}{l}\text { United States } \\
\text { (2003)[47] }\end{array}$ & 2001USD & $\begin{array}{l}\text { ER visits and } \\
\text { rehospitalization }\end{array}$ & $\begin{array}{c}\text { Cost savings/patient } \$ 1,418 \text { in } \\
\text { program participants vs non- } \\
\text { participants during 6-month follow- } \\
\text { up }\end{array}$ & $\$ 1,919$ \\
\hline
\end{tabular}

CR, Cardiac Rehabilitation; PPP, Purchasing Power Parity; USD, US Dollar; CAD, Canadian Dollar; SEK, Swedish Krona; ER, Emergency Room 